\title{
Simvastatin Induces Osteogenic Differentiation and Suppresses Adipogenic Differentiation in Primarily Cultured Human Adipose-Derived Stem Cells
}

\author{
So-Hyun Sun ${ }^{1}$, II Kyu LeE ${ }^{1,3}$, Jeewon LeE ${ }^{2}$, Insop SHIm ${ }^{3,4}$, Se Hong KIm ${ }^{1,4}$, and Kyung-Soo KIm ${ }^{1,3,4, *}$ \\ ${ }^{1}$ Department of Family Medicine, The Catholic University of Korea, Seoul 137-701, Republic of Korea, \\ ${ }^{2}$ Department of Biochemistry, McGill University, Quebec, H3A 2T5, Canada, ${ }^{3}$ Department of Integrative Medicine, \\ ${ }^{4}$ Research Center of Behavioral Medicine, The Catholic University of Korea, Seoul 137-701, Republic of Korea
}

(Received August 20, 2009; Revised September 8, 2009; Accepted September 9, 2009)

\begin{abstract}
Recent in vitro and in vivo animal studies have reported that statin, a cholesterol-lowering drug, stimulate osteogenic differentiation. In the present study, we investigated the effect of simvastatin on osteogenic and adipogenic differentiation in primarily cultured human adipose-derived stem cells (hADSCs). The simvastatin treatment significantly increased the positive cell numbers in alkaline phosphatase and von Kossa staining, and enhanced the expression levels of bone morphogenic protein (BMP)-2, core binding factor alpha 1 (cbfa1), collgen type I and osteonectin mRNAs. Lastly, hADSCs were cultured in the adipogenic media with or without simvastatin to examine the effect of simvastatin on adipogenic differentiation. In the RT-PCR analysis, there were notable decreases in mRNA expression of aP1, C/EBP- $\alpha$ and PPAR- $\gamma$ in hADSCs cultivated in simvastatin-added medium, compared to those in simvastatin-free medium. It suggests that the adipogenic differentiation was significantly inhibited by simvastatin treatment. These observations indicate that simvastatin induces osteogenic differentiation and suppresses adipogenic differentiation in hADSCs.
\end{abstract}

Keywords: Simvastatin, Human adipose-derived stem cells, Osteogenic differentiation, Adipogenic differentiation

\section{INTRODUCTION}

Although bone marrow (BM) is a primary source of multipotent mesenchymal stem cells (MSCs), BM harvest is a highly invasive procedure and the number, differentiation potential, and maximal life span of MSCs from BM decline with increasing age. Since the first description by Friedenstein (Friedenstein et al., 1974), much work has shown their properties in vitro and in vivo (Pittenger et al., 1999; Deans and Moseley, 2000; Fibbe and Noort, 2003). MSCs have considerable therapeutic potential in pre-clinical (Kopen et al., 1999; Petite et al., 2000) and clinical (Horwitz et al., 1999; Koç et al., 2000; Chen et al., 2004; Le Blanc et al., 2004; Jaquet et al., 2005) studies for the treatment/ regeneration of neuronal degeneration, osteo-

${ }^{*}$ Corresponding author

Tel: +82-2-2258-6284 Fax: +82-2-537-8979

E-mail: kskim@catholic.ac.kr genesis imperfecta, graft versus host disease, support of hematopoietic engraftment, metabolic diseases, bone and cartilage tissues, as well as renal and myocardial infarction. Adipose tissue (AT), like bone marrow, is derived from the embryonic mesenchyme and contains a stroma that is easily isolated. A putative stem cell population within the adipose stromal compartment can be isolated from human lipoaspirates and, like MSCs, differentiate toward the osteogenic, adipogenic, myogenic, and chondrogenic lineages. AT can be obtained by a less invasive method and in larger quantities than BM, but few studies have tested human adipose-derived stem cells (hADSC).

Statins, inhibitors of 3-hydroxy-3-methylglutarylcoenzyme A (HMG-CoA) reductase, have revolutionized the treatment of hypercholesterolemia by effectively lowering plasma cholesterol and being well tolerated to reduce cardiovascular morbidity and mortality (Shepherd et al., 1995; Vaughan et al., 2000; Sugiyama et al., 2000; Stancu 
and Sima, 2001; Togel et al., 2005; Blinc and Poredos, 2007; Karpisek et al., 2007; Lin et al., 2008). Statins have activity beyond lipid-lowering effects (Vaughan et al., 2000), including the potential to induce osteogenic changes on bones (Lips, 2002; Ho et al., 2009). Statins promote osteoblasts to synthesize bone morphogenic protein 2 (BMP2) (Gori et al., 1999; Mundy et al., 1999), a growth factor that causes osteoblasts to differentiate, proliferate, mature, and form new bone in vitro and in vivo, and also inhibits adipocyte differentiation (Gimble et al., 1995). Here, we investigated the effect of simvastatin on osteoblastic and adipocytic differentiation in hADSCs in vitro.

\section{MATERIALS AND METHODS}

\section{Procurement of specimen}

Adipose tissue samples were isolated from lipoaspirates obtained during elective liposuction surgery. These patients did not have significant medical or medication history. The approval for this study was obtained from the institutional review boards (IRB) of the Catholic University of Korea, College of Medicine, and informed consent was given according to the Declaration of Helsinki.

\section{Isolation and Culture of preadipocytes}

hADSC isolation was performed as described by $\mathrm{Im}$ (Im et al., 2005). Briefly, lipoaspirates were washed three times with phosphate-buffered saline (PBS, Gibco-BRL, Grand Island, NY, USA) containing 10\% antibiotic/antimycotic (P/S, Gibco-BRL) and $1 \%$ bovine serum albumin (BSA, Bovogen, Ogilvie St. Essendon Vic, Australia), and the extracellular matrix was digested with $0.06 \%$ collagenase (collagenase type I, Invitrogen Corporation, Carlsbad, CA, USA), shaken for $2 \mathrm{~h}$ at $37^{\circ} \mathrm{C}$, followed by filtration through $40-\mu \mathrm{m}$ nylon mesh (Cell strainer, BD Falcon, Two Oak Park, Bedford, MA, USA). Erythrocytes were removed using erythrocyte lysis buffer $(0.15 \mathrm{M}$ ammonium chloride, $1.0 \mathrm{mM}$ potassium bicarbonate, and $0.1 \mathrm{mM}$ EDTA) and the remaining cells were seeded in culture flasks under conditions identical to preadipocytes. The cells were cultured in Minimum Essential Medium $\alpha$ (MEM $\alpha$, Gibco-BRL, Grand Island, NY, USA) supplemented with $10 \%$ fetal bovine serum (FBS, Hyclone, Logan, UT, USA) and $1 \%$ Penicillin-Streptomycin (P/S, Gibco-BRL) in a humidified atmosphere containing $5 \% \mathrm{CO}_{2}$ at $37^{\circ} \mathrm{C}$. After $24 \mathrm{~h}$, the cultured cells were washed with PBS to remove any nonadherent material. The medium was replaced twice a week during the expansion period. When the cells reached $80 \%$ confluence, they were detached from the culture dish using 1X Trypsin-EDTA (Gibco BRL, Grand Island, NY, USA), and washed with PBS, followed by re-counting and re-plating. The cells were suspended in cryo-preservation medium containing 50\% MEM $\alpha, 40 \%$ FBS, and 10\% dimethylsulfoxide (DMSO, St. Louis MO, USA) after culturing through passage 2 .

\section{Colony-forming unit-fibroblast (CFU-F) assay}

The colony-forming unit-fibroblast assay (CFU-F) was performed as described by Castro-Malaspina (Castro-Malaspina et al., 1980). Briefly, hADSCs were plated onto $10 \mathrm{~cm}$ dishes at $4 \times 10^{6}$ cells (in triplicate). After 8 to 12 days, CFU-F formation was examined and the cells, stained with crystal violet, were counted.

\section{Flow cytometry}

Flow cytometry on the cell surface markers STRO-1, CD105, and CD34 was conducted to separate MSCs from hADSCs. During passage 3, the hADSCs were harvested into a test tube (Becton Dickinson, Franklin Lakes, NJ, USA) at $1 \times 10^{7}$ cells $/ \mathrm{ml}$, and washed 3 times with wash buffer $\left(0.2 \% \mathrm{BSA}, 0.1 \% \mathrm{NaN}_{3}, 0.5 \mathrm{mM}\right.$ EDTA). The conjugated to fluorescein isothicyanate (FITC) or phycoerythrin (PE) antibodies to CD34 (BD Bioscience) and CD105 (Serotec Ltd, Station Approach, Kidlington, Oxford, UK), were treated for an hour and washed 3 times with wash buffer, followed by flow cytometry. The same procedure was used for STRO-1 (Human anti-mouse monoclonal antibody, IgM subclass; R\&D system, Minneapolis, MA, USA), except with a secondary FITC antibody.

\section{Osteogenic differentiation}

During passage 3 , hADSCs were plated onto 12 well plates $\left(6 \times 10^{5}\right.$ cells/well) and treated with: normal medium (complete MEM $\alpha$ ), osteogenic differentiation medium (MEM $\alpha$ including $0.1 \mu \mathrm{M}$ dexamethasone, $10 \mu \mathrm{M}$ glycerol phosphate, and $50 \mu \mathrm{M}$ L-ascorbic acid 2-phosphate), MEM $\alpha$ included $100 \mathrm{ng} / \mathrm{ml}$ of rhBMP2, or $1 \mu \mathrm{M}$ of simvastatin. Media was replaced every three days.

\section{Adipogenic differentiation}

hADSCs at passage 3 were plated onto 6 well plates $\left(1.5 \times 10^{6} \mathrm{cells} /\right.$ well) and cultured in adipogenic media $(0.5$ $\mathrm{mM}$ isobutyl methylxanthine, $1 \mathrm{uM}$ dexamethasone, $10 \mathrm{uM}$ insulin, $200 \mathrm{UM}$ indomethacin) with or without $1 \mu \mathrm{M}$ of simvastatin. Media was changed every three days.

\section{Alkaline phosphatase (ALP) staining}

Plates were washed 3 times with sterile triple-distilled water at 7, 14, 21 and 28 days after the first treatment date. 
The plates were fixed with Citrate-Acetone-Formaldehyde fixer solution (Sigma; St. Louis, MO, USA), and washed 3 times with sterile triple-distilled water. They were stained with Alkaline-dye mix (Nitrite, FRV-alkaline, Naphthol AS-BI alkaline solution; Sigma) in the dark for 20 minutes at normal temperature. Cells were washed 3 times, counterstained with Hematoxylin (Sigma), and washed again 3 times with water. Plates were observed an inverted microscope (IX2-SLP; Olympus, Japan).

\section{von Kossa and oil red $O$ staining}

Plates were washed 3 times with sterile triple-distilled water, fixed with 4\% paraformaldehyde (Merck; Frankfurter Str., Darmstadt, Germany) for 15 minutes at normal temperature, and washed again 3 times with water. Using 1\% silver nitrate (Merck; Frankfurter Str., Darmstadt, Germany) solution, the cells were stained for $30 \mathrm{~min}$ in the dark or for $30 \mathrm{~min}$ with $5 \%$ oil reo $\mathrm{O}$ (Sigma), followed by washing. For von Kossa staining, the plates were left for 1 $\mathrm{h}$ under UV and counterstained with $0.1 \%$ Eosin (Sigma; St. Louis, MO, USA).

\section{Reverse transcriptase-polymerase chain reaction (RT-PCR)}

Plates were washed with PBS (Gibco BRL) after 7, 14, 21 and 28 days of osteogenic differentiation or 7 and 14 days of adipogenic differentiation. Cells were collected using a cell scraper (Sarsted, Inc, Newton, NC, USA) and the RNA was separated with a QIAGEN RNA extraction kit (QIAGEN, Hilden, Germany), followed by RT-PCR for osteogenic or adipogenic marker primers and RT-PCR premix (Bioneer, Korea). Primers and reaction conditions are described Table I.

\section{Lipolysis assay}

hADSCs in passage 3 were plated on 96 well plates, $5 \times 10^{4}$ cells/well, and treated with normal media (MEM $\left.\alpha\right)$ or adipogenic media with or without $1 \mu \mathrm{M}$ simvastatin. After 7 or 14 days, the lipolysis assay was performed (Brasaemle et al., 2004).

\section{Quantitative analysis}

Quantitative analysis of ALP, von Kossa, and Oil red O staining were measured by Optimas program (Meyer Instruments, Inc; Langham Creek, Houston, TX, USA) and expressed as mean percentage area $\pm \mathrm{SD}$.

\section{RESULTS}

\section{Cell and colony morphology}

After 12 days of culture, hADSCs exhibited a fusiform, spindle-shaped appearance (Fig. 1). The cells proliferated and formed morphologically homogenous colonies. Morphological observation at $8 \mathrm{~h}$ showed segregated, spindle-shaped cells starting to adhere to the bottom of the plate. Colony formation on day 12 was 5 to 8 colonies per $100 \mathrm{~mm}$ plate (Fig. 1A and B).

\section{Cell sorting}

FACS analysis of the surface antigens, CD 34, STRO-1, CD105, and CD166 showed no change in CD34 levels, but STRO-1 (Fig. 1C), CD105 (Fig. 1D), and CD166 (Fig. 1E) showed a positive expression of $93 \%, 92 \%$, and $95 \%$, respectively.

Table I. Used primers

\begin{tabular}{|c|c|c|c|c|}
\hline \multicolumn{2}{|c|}{ Name } & \multicolumn{2}{|r|}{ Primer } & \multirow{2}{*}{$\begin{array}{r}\text { Annealing } \\
51^{\circ} \mathrm{C}\end{array}$} \\
\hline Osteogenic & Runx2/Cbfa1 & $\begin{array}{l}\text { Forward } \\
\text { Reverse }\end{array}$ & $\begin{array}{l}\text { 5'-CCG CAC GAC AAC CGC ACC AT-3' } \\
\text { 5'-CGC TCC GGC CCA CAA ATC TC-3' }\end{array}$ & \\
\hline & ALP & $\begin{array}{l}\text { Forward } \\
\text { Reverse }\end{array}$ & $\begin{array}{l}\text { 5'-TGG AGC TTC AGA AGC TCA ACA CCA-3' } \\
\text { 5'-ATC TCG TTG TCT GAG TAC CAG TC-3' }\end{array}$ & $58^{\circ} \mathrm{C}$ \\
\hline & Collagen type I & $\begin{array}{l}\text { Forward } \\
\text { Reverse }\end{array}$ & $\begin{array}{l}\text { 5'-GGA CAC AAT GGA TTG CAA GG-3' } \\
\text { 5'-TAA CCA CTG CTC CAC TCT GG-3' }\end{array}$ & $58^{\circ} \mathrm{C}$ \\
\hline \multirow[t]{3}{*}{ Adipogenic } & $\mathrm{aP2}$ & $\begin{array}{l}\text { Forward } \\
\text { Reverse }\end{array}$ & $\begin{array}{l}\text { 5'-GCT TTG CCA CCA GGA AAG TG-3' } \\
\text { 5'-ATG ACG CAT TCC ACC ACC AG-3' }\end{array}$ & $60^{\circ} \mathrm{C}$ \\
\hline & C/EBP a & $\begin{array}{l}\text { Forward } \\
\text { Reverse }\end{array}$ & $\begin{array}{l}\text { 5'-AGA AAG GGG TGG AAA CAT AGG-3' } \\
\text { 5'-GAA AGC TGA GGG CAA AGG-3 }\end{array}$ & $58^{\circ} \mathrm{C}$ \\
\hline & PPAR- $\gamma$ & $\begin{array}{l}\text { Forward } \\
\text { Reverse }\end{array}$ & $\begin{array}{l}\text { 5'-AAA CTC TGG GAG ATT CTC CT-3’' } \\
\text { 5'-TCT TGT GAA TGG AAT GTC TT-3’ }\end{array}$ & $56^{\circ} \mathrm{C}$ \\
\hline Control & GAPDH & $\begin{array}{l}\text { Forward } \\
\text { Reverse }\end{array}$ & $\begin{array}{l}\text { 5'-CCG CAT CTT CTT TTG CGT CGC-3' } \\
\text { 5'-GCA ACT GTG AGG AGG GGA GAT TCA G-3' }\end{array}$ & $52^{\circ} \mathrm{C}$ \\
\hline
\end{tabular}

The reaction conditions were as follows: 1 . incubation at $94^{\circ} \mathrm{C}$ for $2 \mathrm{~min}, 2$. denaturation at $94^{\circ} \mathrm{C}$ for $45 \mathrm{~s}, 3$. annealing at $51^{\circ} \mathrm{C}(\mathrm{Run} \times 2 / \mathrm{Cbfa} 1)$ or $58^{\circ} \mathrm{C}$ (ALPandColl) for $45 \mathrm{~s}, 4$. polymerization at $72^{\circ} \mathrm{C}$ for $60 \mathrm{~s}$ for 32 cycles, 5 . extension at $72^{\circ} \mathrm{C}$ for 5 min, 6 . The amplified products were analyzed twice by means of $2 \%$ agarose gel electrophoresis. 


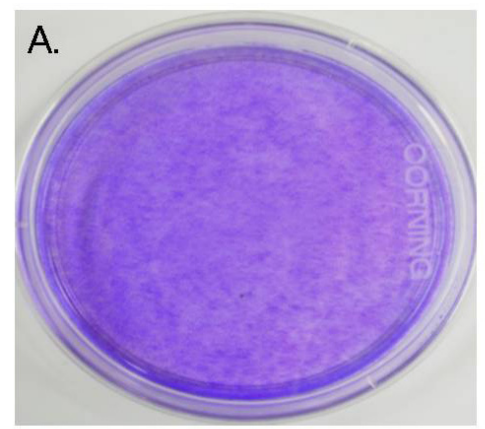

C.

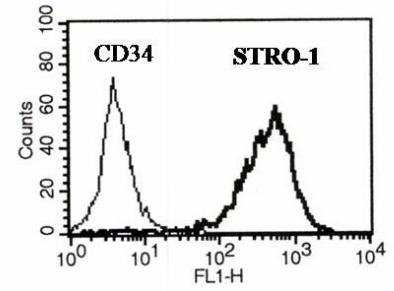

D.

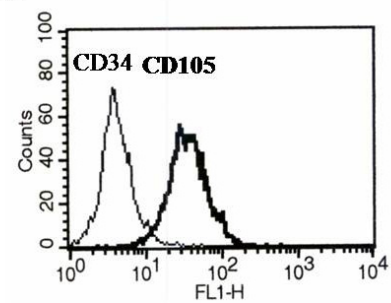

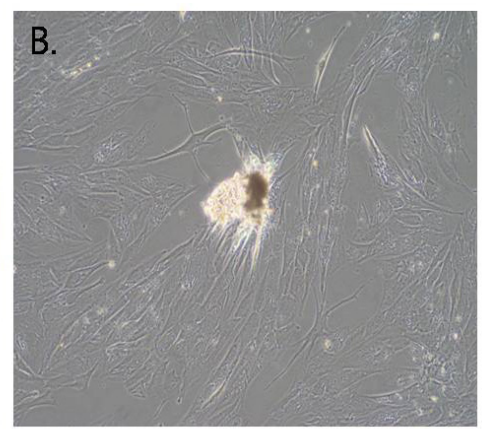

E.

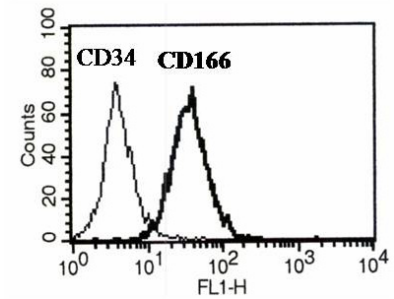

Fig. 1. Conformation of mesenchymal stem cell on hADSCs by colony formation unit (CFU) assay and fluorescence-activated cell sorting (FACs). hADSCs from human adipose tissue were seeded in $100 \mathrm{~mm}$ culture dish. After 8 days, the cells were stained with crystal violet (A, B). During P 3, the cells were harvested. The antibodies of CD34, STRO-1, CD105 and CD166, to which fluorescein isothicyanate (FITC) was adhered were analyzed by FACs. CD34 was used as a control (C-E). (A) hADSCs (100 mm dish), (B) hADSCs (×100), (C) stained STRO-1, (D) stained CD105 and (E) stained CD 166.

\section{Confirmation of osteogenesis induction}

Alkaline phosphatase staining (ALP): We performed ALP staining after hADSC treatment with BMP2, osteogenic differentiation media, or simvastatin for $7,14,21$, or 28 days (Fig. 2A-D and I). ALP measures the presence of mineralization by forming a blue product. Osteogenic media (Fig. 2B), BMP2 (Fig. 2C), and simvastatin (Fig. 2D) all increased ALP staining after 7 days, suggesting the induction of osteogenic differentiation. Osteogenic differentiation media and BMP2 showed darker ALP staining with longer treatment, but simvastatin did not, confirming that no further osteogenic differentiation occurred after 7 days (Fig. 2l).

von Kossa staining: We used von Kossa staining to test whether calcium accumulation occurred during osteogenic differentiation (Fig. 2E-H and J). As for ALP staining, simvastatin treatment induced maximal von Kossa staining by day 7 . Osteogenic differentiation media and BMP2 induced dramatic staining after 14 days, but the color continued to develop (Fig. 2E-H and J). Shorter simvastatin treatments $(3,6,9$, or 12 days) showed that staining appeared by day 3 and plateaued at day 9 (Fig. 3).

Osteogenic marker gene expression: Simvastatin treatment time-dependently increased mRNA expression of cbfa1, osteocalcin, collagen type I, osteonectin, and BMP2 (Fig. 4).

\section{Confirmation of adipogenesis inhibition}

Oil red $O$ staining: Adipogenic media induced the differentiation of hADSCs into adipocytes, but $1 \mu \mathrm{M}$ simvastatin blocked this activity by about 50\% (Fig. 5A-G). The adipocytes existed in clusters with cytoplasmic lipid droplets that were positive for Oil Red O stain, with fewer droplets seen after simvastatin treatment.

Adipogenic marker gene expression: Adipogenic media also time-dependently increased mRNA levels of aP1, $\mathrm{C} / \mathrm{EBP} \alpha$, and PPAR $\gamma$, but $1 \mu \mathrm{M}$ simvastatin blocked this activity (Fig. $5 \mathrm{H}$ and I).

Lipolysis assay: Treatment with adipogenic media for 14 days induced higher levels of glycerol in hADSC, and 1 $\mu \mathrm{M}$ simvastatin further increased these levels over an additional 3 days (Fig. 6).

\section{DISCUSSION}

Multipotent mesenchymal stromal cells (MSC), also called mesenchymal stem cells, are characterized by adherence to plastic when maintained in standard cultures in vitro, by expression of the surface antigens, CD105 and CD90, but a lack of the hematopoietic markers CD34 and $\mathrm{CD} 45$, and by differentiation into osteoblasts, adipocytes, and chondroblasts in vitro (Dominici et al., 2006). A putative stem cell population within the adipose stromal com- 


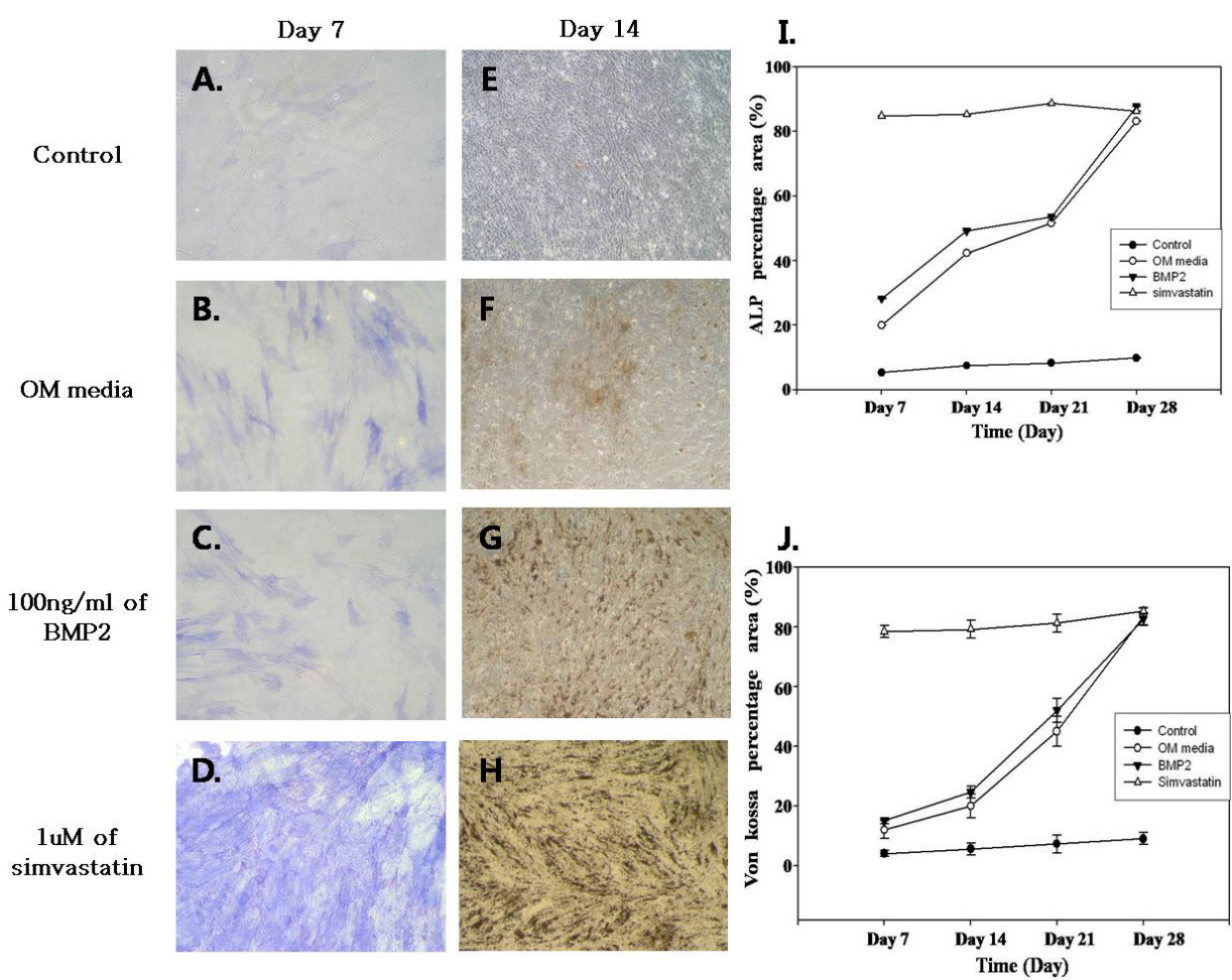

Fig. 2. Effects of osteogenic media, BMP-2, and simvastatin on alkaline phosphatase expression and mineralization in hADSCs $(\times 100)$. During P3, the cells were separated into 12-well plate and they were incubated in MEM, OM media, $100 \mathrm{ng} / \mathrm{ml}$ of BMP-2 and 1 uM of simvastatin, separately. After 7, 14, 21 and 28 days, the cells were stained with Alkaline-dye mix or $1 \%$ silver nitrate solution and observed with inverted microscope. MEM was used as a negative control while OM media and BMP-2 were used as a positive control. (A) Treatment of MEM after 7 days (ALP), (B) Treatment of OM media after 7 days (ALP), (C) Treatment of $1 \mathrm{ng} / \mathrm{ml}$ BMP-2 after 7 days (ALP), (D) Treatment of $1 \mathrm{uM}$ simvastatin after 7 days (ALP), (E) Treatment of MEM after 14 days (von Kossa), (F) Treatment of OM media after 14 days (von Kossa), (G) Treatment of $1 \mathrm{ng} / \mathrm{ml} \mathrm{BMP-2}$ after 14 days (von Kossa), (H) Treatment of $1 \mu \mathrm{M}$ simvastatin after 14 days (von Kossa) to (I), Quantitative analysis of alkaline phosphatase expression and (J) Quantitative analysis mineralization effect.

partment can be isolated from human lipoaspirates and, like MSCs, differentiate toward the osteogenic, adipogenic, myogenic, and chondrogenic lineages. AT can be obtained by a less invasive method and in larger quantities than BM. We separated hADSCs from lipoaspirates using flow cytometry of the cell surface markers, STRO-1, CD105, and CD34 (Fig. 1C-E). Mundy et al. (1999) reported the stimulation of bone formation in vitro and in rodents by statins (Mundy et al., 1999). The statins are the most effective and best-tolerated agents for treating dyslipidemia. These drugs are competitive inhibitors of 3-hydroxy-3- methylglutaryl coenzyme A (HMG-CoA) reductase, which catalyzes an early, rate-limiting step in cholesterol biosynthesis. Statins exert their major effect-reduction of LDL levels-through a mevalonic acid-like moiety that competitively inhibits HMG-CoA reductase.

Lovastatin inhibits adipogenic and stimulates osteogenic differentiation in BM mesenchymal cell cultures ( $\mathrm{Li}$ et al.,
2003) and in mouse BM stromal cells (Song et al., 2003). The inhibition of mevalonate synthesis prevents the synthesis of isoprenoid precursors (geranyl and farnesyl pyrophosphates), which are substrates for prenylation of small GTP binding proteins (Rho, Rac, Rab). This decrease in prenylation inhibits osteoclast activity because these small proteins cannot anchor to the membrane of osteoclasts because they lack a lipid chain. Statins promote osteoblasts to synthesize BMP2, a growth factor that causes osteoblasts to differentiate, proliferate, mature, and form new bone in vitro and in vivo, as well as inhibits adipocyte differentiation. Simvastatin increases bone volume and induce the expression of osteogenic markers, like BMP2, osteocalcin, osteopontin, and alkaline phosphatase (Ohnaka et al., 2001; Gonyeau, 2005).

Statin users showed a trend toward fewer hip fractures and improved hip bone BMD (Bauer et al., 2004), but meta-analysis of the two randomized clinical trials did not 

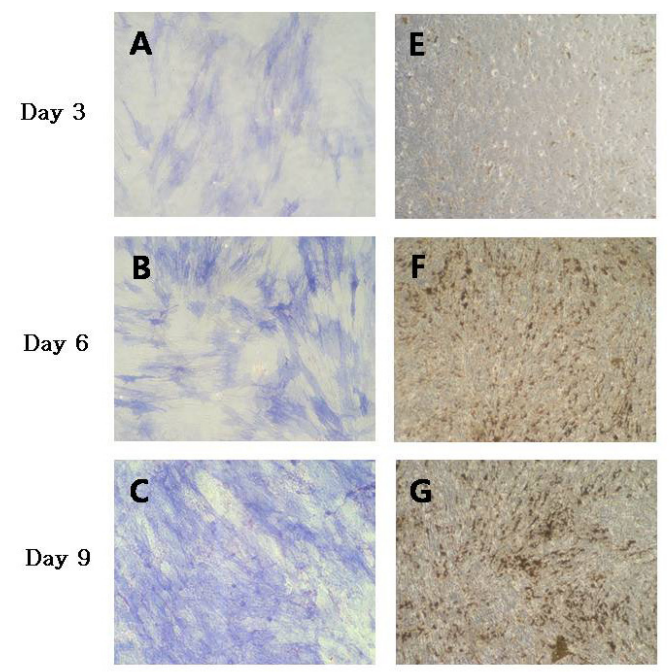

I.
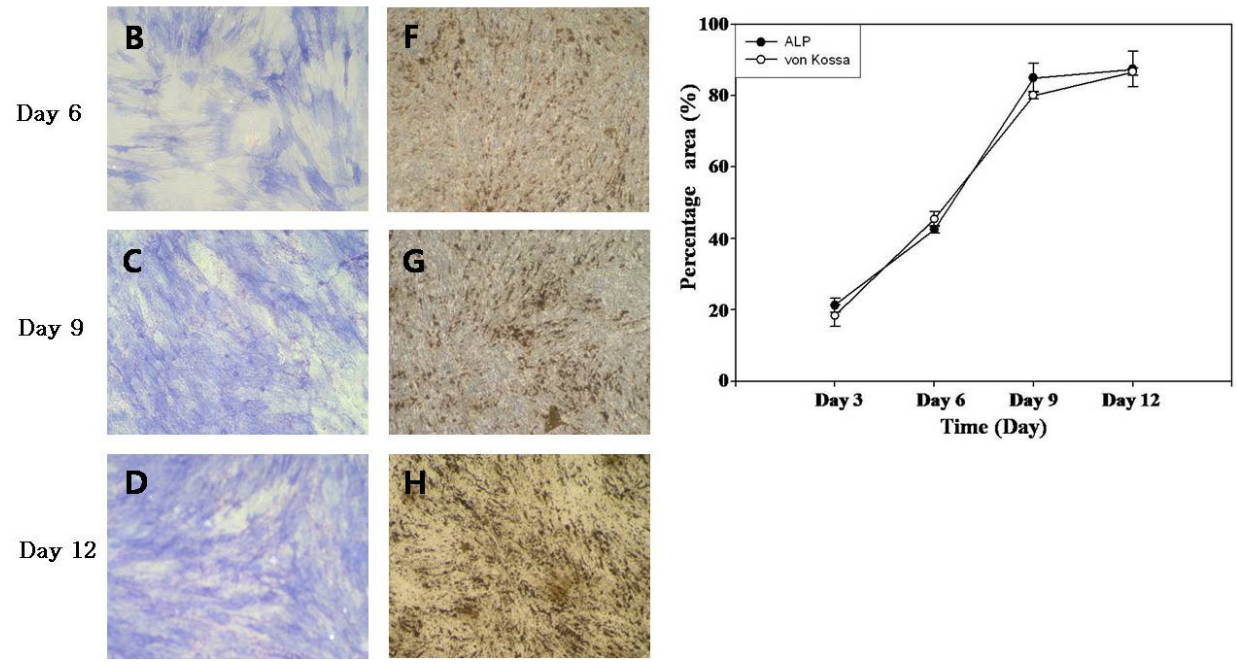

Fig. 3. Earlier effects of simvastatin $(1.0 \mu \mathrm{M})$ on alkaline phosphatase expression and mineralization in hADSCs using ALP and von Kossa staining $(\times 100)$. During P3, hADSCs were seeded 12-well plate and were incubated in $1 \mu \mathrm{M}$ of simvastatin. After 3, 6, 9 and 12 days, the cells were stained with Alkaline-dye mix or $1 \%$ silver nitrate solution, and they were observed with inverted microscope. (AD) ALP staining, (E-H) von kossa staining and (I) Quantitative analysis of alkaline phosphatase expression and mineralization effect.

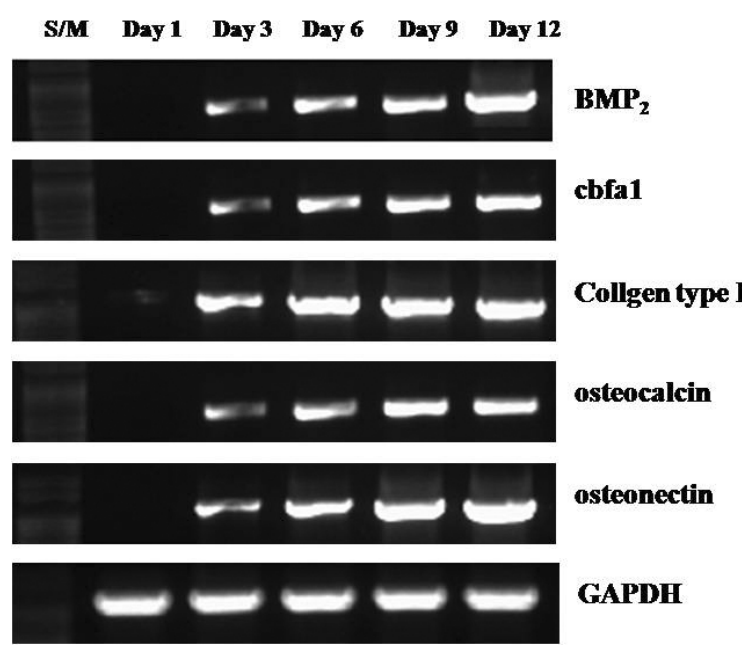

Fig. 4. Simvastatin increases osteogenic marker genes expression, such as cbfa1, osteocalcin, collgen type I, osteonectin and BMP-2. The hADSCs were treated with $1 \mu \mathrm{M}$ of simvastatin. After 1, 3, 6, 9 and 12 days, osteogenic marker genes expression were observed using RT-PCR.

support a protective effect on hip or non-spine fractures (Pedersen and Kjekshus, 2000; Reid et al., 2001). Among the 13,592 participants in the National Health and Nutritio- nal Examination Survey (NHANES) III who did not report the use of lipid-lowering drugs, there was no correlation between lipid levels and bone mineral density (BMD) (Solomon et al., 2005). Thus, it seems unlikely that hyperlipidemia could explain the discrepancies in the bone effects of statins between observational studies and randomized controlled trials. Finally, the physical activity of patients and controls was not quantified in the studies, although it is associated with a higher BMD. Statins require higher doses animal studies (10-fold) for bone effects than are used in dyslipidemia, and long-term treatment may be required to see activity.

We found that hADSCs treated with osteogenic media and BMP2 were partially positive for ALP staining after 7 days (Fig. 2A-D), but staining was stronger in the simvastatin group and plateaued at 7 days (Fig. 2D and I), suggesting earlier osteogenic differentiation. BMP2 produced a darker red color than osteogenic differentiation media(Fig. 2A-C). von Kossa staining, a measure of calcium accumulation, showed similar results: simvastatin produced staining that plateaued after 7 days (Fig. 2H), whereas differentiation media and BMP2 color darkened over time (Fig. 2E-G). Simvastatin produced staining as early as 3 days and plateaued between 7-9 days (Fig. 3).

Simvastatin time-dependently increased mRNA levels 

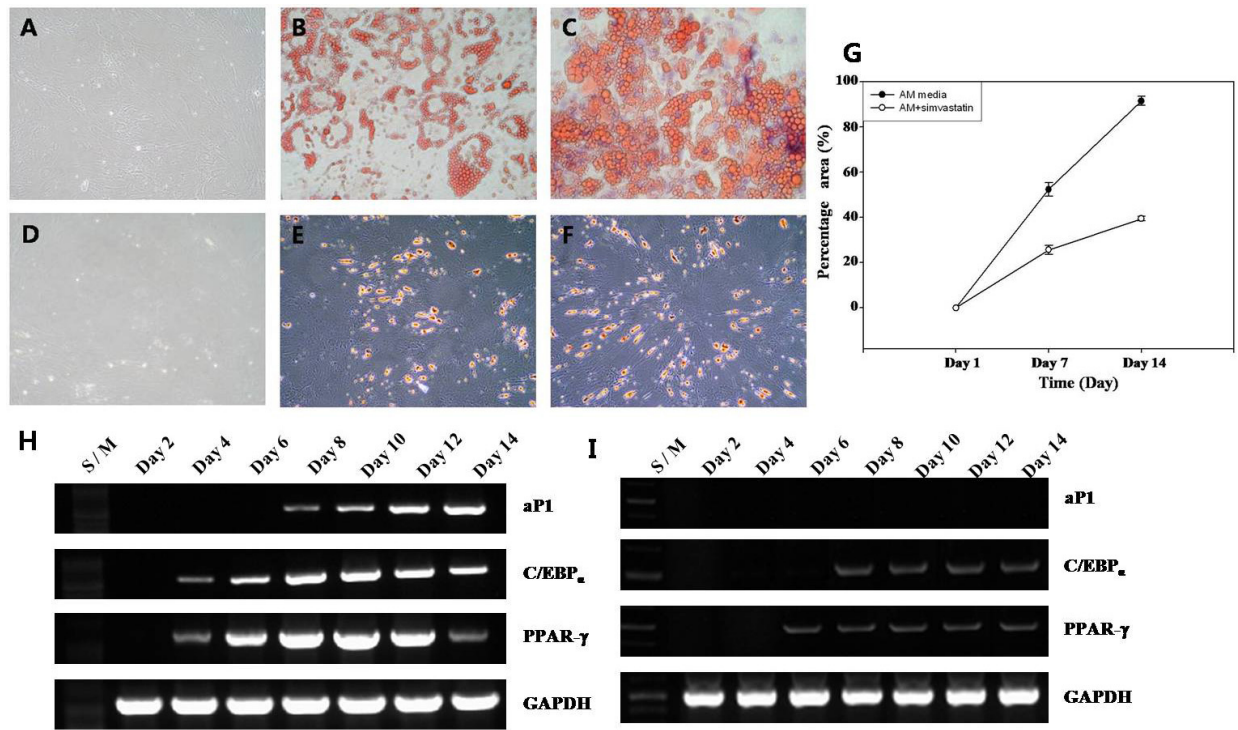

Fig. 5. Simvastatin inhibits adipogenic differentiation in hADSCs. The hADSCs were treated adipogenic media with or without $1 \mu \mathrm{M}$ of simvastatin. After 1, 7 and 14 days, hADSCs were stained with $5 \%$ Oil red $O$ reagent and they were observed with inverted microscope. (A) After 1 day of treatment in adipogenic media, (B) After 7 days of treatment in adipogenic media, (C) After 14 days of treatment in adipogenic media, (D) After 1day of treatment in adipogenic media with $1 \mu \mathrm{M}$ of simvastatin, (E) After 7 days of treatment in Adipogenic media with $1 \mu \mathrm{M}$ of simvastatin, (F) After 14 days of treatment in Adipogenic media with $1 \mu \mathrm{M}$ of simvastatin, (G) Quantitative analysis of $A-F$ and Adipogenic marker genes expression without $(H)$ and with (I) $1 \mu \mathrm{M}$ simvastatin.

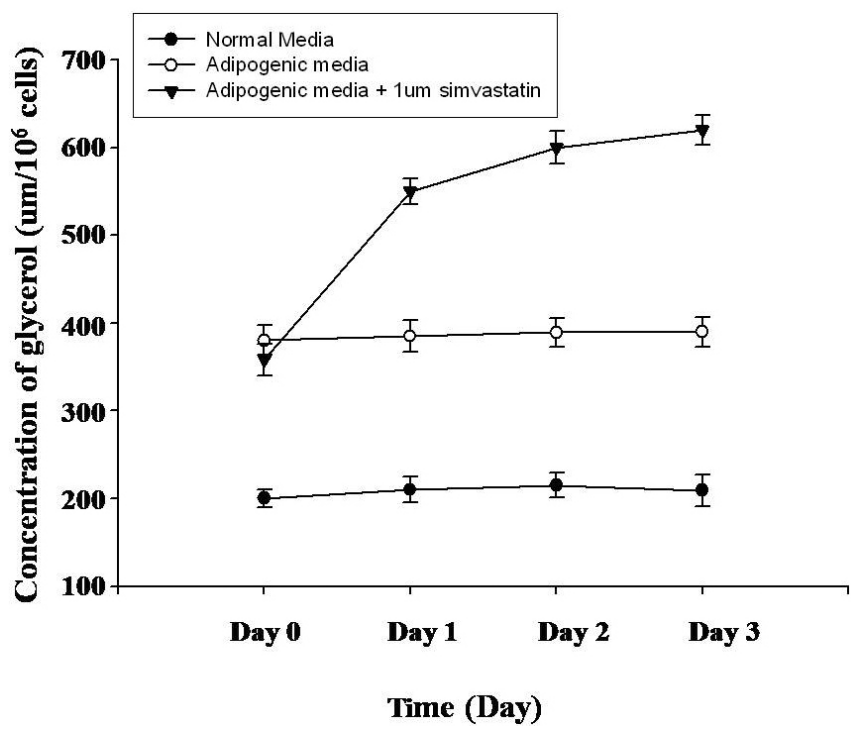

Fig. 6. Lipolysis assay containing Adipocyte-derived mesenchymal cells. hADSCs were incubated in adipogenic media. After 14 days, the cells were treated with $1 \mu \mathrm{M}$ of simvastatin. 1 , 2 and 3 days later, glycerol concentration was analyzed by ELISA method.

of cbfa1, osteocalcin, collagen type I, osteonectin, and BMP2 (Fig. 4), as well as increased ALP activity (2-fold above basal) (Fig. 2l). Taken together, simvastatin treatment induces osteoblastogenesis.

We next measured adipocyte differentiation using Oil Red $\mathrm{O}$ staining and changes in $\mathrm{AP} 1, \mathrm{C} / \mathrm{EBP} \alpha$, and PPAR $\gamma$ mRNA levels (Fig. 5). Simvastatin $(1 \mu \mathrm{M})$ inhibited the adipocyte differentiation induced by adipogenic media by about $50 \%$. The adipocytes existed in clusters with cytoplasmic lipid droplets that were positive for Oil Red O stain, with fewer droplets seen after simvastatin treatment (Fig. 5A-G). Simvastatin also induced lipolysis, as shown by increased glycerol levels after 3 days of treatment in differentiated hADSCs (Fig. 6).

In conclusion, our data suggest that human AT contains multipotent cells and may represent an alternative stem cell source to bone marrow-derived MSCs. Simvastatin increased osteogenic differentiation and decreased adipogenesis in hADSCs. Further studies about the effects of long term use of simvastatin on body composition and bone remodeling in humans are needed. In addition, other statins may have better affects, as some statins are lipophilic (simvastatin and lovastatin, which are prodrugs) and others are more hydrophilic (pravastatin, atorvastatin, fluvastatin). These differences may affect bone bioavailability and influence their therapeutic effects. 


\section{ACKNOWLEDGMENTS}

The authors thank other members of our laboratory for their valuable assistance. This study was supported by a grant from the Korea Health 21 R \& D Project, Ministry of Health and Welfare, Republic of Korea (project No. A060093) and the Korean Society for the Study of Obesity.

\section{REFERENCES}

Bauer, D. C., Mundy, G. R., Jamal, S. A., Black, D. M., Cauley, J. A., Ensrud, K., E., van der Klift, M. and Pols, H. A. (2004). Use of statins and fracture: results of 4 prospective studies and cumulative meta-analysis of observational studies and controlled trials. Arch. Intern. Med. 164, 146-152.

Blinc, A. and Poredos, P. (2007). Pharmacological prevention of atherothrombotic events in patients with peripheral arterial disease. Eur. J. Clin. Invest. 37, 157-164.

Brasaemle, D. L., Dolios, G., Shapiro, L. and Wang, R. (2004). Proteomic analysis of proteins associated with lipid droplets of basal and lipolytically stimulated 3T3-L1 adipocytes. J. Biol. Chem. 279, 46835-46842.

Castro-Malaspina, H., Gay, R. E., Resnick, G., Kapoor, N., Meyers, P., Chiarieri, D., McKenzie, S., Broxmeyer, H. E. and Moore, M. A. (1980). Characterization of human bone marrow fibroblast colony-forming cells (CFU-F) and their progeny. Blood 56, 289-301.

Chen, S. L., Fang, W. W., Ye, F., Liu, Y. H., Qian, J., Shan, S. J., Zhang, J. J., Chunhua, R. Z., Liao, L. M., Lin, S. and Sun, J. P. (2004). Effect on left ventricular function of intracoronary transplantation of autologous bone marrow mesenchymal stem cell in patients with acute myocardial infarction. Am. J. Cardiol. 94, 92-95.

Deans, R. J. and Moseley, A. B. (2000). Mesenchymal stem cells: biology and potential clinical uses. Exp. Hematol. 28, 875-884.

Dominici, M., Le Blanc, K., Mueller, I., Slaper-Cortenbach, I., Marini, F., Krause, D., Deans, R., Keating, A., Prockop, D. J. and Horwitz, E. (2006). Minimal criteria for defining multipotent mesenchymal stromal cells. The International Society for Cellular Therapy position statement. Cytotherapy 8, 315-317.

Fibbe, W. E. and Noort, W. A. (2003). Mesenchymal stem cells and hematopoietic stem cell transplantation. Ann. N. Y. Acad. Sci. 996, 235-244.

Friedenstein, A. J., Deriglasova, U. F., Kulagina, N. N., Panasuk, A. F., Rudakowa, S. F., Luriá, E. A. and Ruadkow, I. A (1974). Precursors for fibroblasts in different populations of hematopoietic cells as detected by the in vitro colony assay method. Exp. Hematol. 2, 83-92.

Gimble, J. M., Morgan, C., Kelly, K., Wu, X., Dandapani, V., Wang, C. S. and Rosen, V. (1995). Bone morphogenetic proteins inhibit adipocyte differentiation by bone marrow stromal cells. J. Cell Biochem. 58, 393-402.

Gonyeau, M. J. (2005). Statins and osteoporosis: a clinical review. Pharmacotherapy 25, 228-243.

Ho, M. L., Chen, Y. H., Liao, H. J., Chen, C. H., Hung, S. H., Lee, M. J., Fu, Y. C., Wang, Y. H., Wang, G. J. and Chang, J. K.
(2009). Simvastatin increases osteoblasts and osteogenic proteins in ovariectomized rats. Eur. J. Clin. Invest. 39 296-303.

Horwitz, E. M., Prockop, D. J., Fitzpatrick, L. A., Koo, W. W., Gordon, P. L., Neel, M., Sussman, M., Orchard, P., Marx, J. C., Pyeritz, R. E. and Brenner, M. K. (1999). Transplantability and therapeutic effects of bone marrow-derived mesenchymal cells in children with osteogenesis imperfecta. Nat. Med. 5, 309-313.

Im, G. I., Shin, Y. W. and Lee, K. B. (2005). Do adipose tissue-derived mesenchymal stem cells have the same osteogenic and chondrogenic potential as bone marrowderived cells? Osteoarthr. Cartil. 13, 845-853.

Karpisek, M., Stejskal, D., Kotolova, H., Kollar, P., Janoutova, G., Ochmanova, R., Cizek, L., Horakova, D., Yahia, R. B., Lichnovska, R. and Janout, V. (2007). Treatment with atorvastatin reduces serum adipocyte-fatty acid binding protein value in patients with hyperlipidaemia. Eur. J. Clin. Invest. 37, 637-642.

Koç, O. N., Gerson, S. L., Cooper, B. W., Dyhouse, S. M., Haynesworth, S. E., Caplan, A. I. and Lazarusm, H. M. (2000). Rapid hematopoietic recovery after coinfusion of autologous-blood stem cells and culture-expanded marrow mesenchymal stem cells in advanced breast cancer patients receiving high-dose chemotherapy. J. Clin. Oncol. 18, 307-316.

Kopen, G. C., Prockop, D. J. and Phinney, D. G. (1999). Marrow stromal cells migrate throughout forebrain and cerebellum, and they differentiate into astrocytes after injection into neonatal mouse brains. Proc. Natl. Acad. Sci. U.S.A. 96, 10711-10716.

Lange, C., Tögel, F., Ittrich, H., Clayton, F., Nolte-Ernsting, C., Zander, A. R. and Westenfelder, C. (2005). Administered mesenchymal stem cells enhance recovery from ischemia/reperfusion-induced acute renal failure in rats. Kidney Int. 68, 1613-1617.

Le Blanc, K., Rasmusson, I., Sundberg, B., Götherström, C., Hassan, M., Uzunel, M. and Ringdén, O. (2004). Treatment of severe acute graft-versus-host disease with third party haploidentical mesenchymal stem cells. Lancet $\mathbf{3 6 3}$, 1439-1441.

Li, X., Cui, Q., Kao, C., Wang, G. J. and Balian, G. (2003). Lovastatin inhibits adipogenic and stimulates osteogenic differentiation by suppressing PPARgamma2 and increasing Cbfa1/Runx2 expression in bone marrow mesenchymal cell cultures. Bone 33, 652-659.

Lin, C. P., Chen, Y. H., Lin, W. T., Leu, H. B., Liu, T. Z., Huang, S. L. and Chen, J. W. (2008). Direct effect of statins on homocysteine-induced endothelial adhesiveness: potential impact to human atherosclerosis. Eur. J. Clin. Invest. $\mathbf{3 8}$ 106-116.

Lips, P. (2002). Statins and bone turnover. Eur. J. Clin. Invest. 32, 543-544.

Mahmood, A., Lu, D. and Chopp, M. (2004). Marrow stromal cel transplantation after traumatic brain injury promotes cellular proliferation within the brain. Neurosurgery 55, 1185-1193.

Mundy, G., Garrett, R., Harris, S., Chan, J., Chen, D., Rossini, G., Boyce, B., Zhao, M. and Gutierrez, G. (1999). Stimulation of bone formation in vitro and in rodents by statins. Science 286, 1946-1949.

Ohnaka, K., Shimoda, S., Nawata, H., Shimokawa, H., 
Kaibuchi, K., Iwamoto, Y. and Takayanagi, R. (2001). Pitavastatin enhanced BMP-2 and osteocalcin expression by inhibition of Rho-associated kinase in human osteoblasts. Biochem. Biophys. Res. Commun. 287, 337-342.

Pedersen, T. R. and Kjekshus, J. (2000). Statin drugs and the risk of fracture. 4S Study Group. JAMA 284, 1921-1922.

Petite, H., Viateau, V., Bensaïd, W., Meunier, A., de Pollak, C., Bourguignon, M., Oudina, K., Sedel, L. and Guillemin, G. (2000). Tissue-engineered bone regeneration. Nat. Biotechnol. 18, 959-963.

Pittenger, M. F., Mackay, A. M., Beck, S. C., Jaiswal, R. K., Douglas, R., Mosca, J. D., Moorman, M. A., Simonetti, D. W. Craig, S. and Marshak, D. R. (1999). Multilineage potential of adult human mesenchymal stem cells. Science 284, 143-147.

Reid, I. R., Hague, W., Emberson, J., Baker, J., Tonkin, A., Hunt, D., MacMahon, S. and Sharpe, N. (2001). Effect of pravastatin on frequency of fracture in the LIPID study: secondary analysis of a randomised controlled trial.
Long-term Intervention with Pravastatin in Ischaemic Disease. Lancet 357, 509-512.

Shepherd, J., Cobbe, S. M., Ford, I., Isles, C. G., Lorimer, A. R., MacFarlane, P. W., McKillop, J. H. and Packard, C. J. (1995). Prevention of coronary heart disease with pravastatin in men with hypercholesterolemia. West of Scotland Coronary Prevention Study Group. N. Engl. J. Med. 333, 1301-1307.

Solomon, D. H., Avorn, J., Canning, C. F. and Wang, P. S. (2005). Lipid levels and bone mineral density. Am. J. Med. 118,1414

Song, C., Guo, Z., Ma, Q., Chen, Z., Liu, Z., Jia, H. and Dang, G. (2003). Simvastatin induces osteoblastic differentiation and inhibits adipocytic differentiation in mouse bone marrow stromal cells. Biochem. Biophys. Res. Commun. 308, 458-462.

Vaughan, C. J., Gotto, A. M. and Jr. Basson, C. T. (2000). The evolving role of statins in the management of atherosclerosis. J. Am. Coll Cardiol. 35, 1-10. 